\title{
The Relation between Intergranular Corrosion and Electrochemical Characteristic of Carbon Steel in Carbonic Acid and Sodium Nitrite Solutions
}

\author{
Yong Zhou, Fu an Yan*
}

Key Laboratory of Green Chemical Process, Ministry of Education, Wuhan Institute of Technology, Wuhan 430073, China

Hubei Key Laboratory of Novel Reactor and Green Chemical Technology, Wuhan Institute of Technology, Wuhan 430073, China

*E-mail: yanfuan1818@163.com

doi: $10.20964 / 110338$

Received: 4 January 2016 / Accepted: 8 March 2016 / Published: 1 April 2016

The intergranular corrosion (IGC) and electrochemical characteristic of carbon steel in carbonic acid and sodium nitrite solutions was studied with methods of potentiodynamic polarization and metallographic microscope. The relation between intergranular corrosion and electrochemical characteristic was discussed. The occurrence of IGC was observed on the steel surface when the steel was potentiodynamic polarized in carbonic acid and sodium nitrite mixed solution. Carbon steel showed the typical electrochemical characteristic of active-passive-transpassive in the mixed solution, and the initiation and propagation of IGC was observed only when the steel was potentiodynamic polarized in active-passive transition region, passive region and transpassive region. For carbon steel in the mixed solution, the occurrence of IGC was very closely related to the electrochemical characteristic of active-passive transition: carbonic acid induced the dissolution of grain boundaries and sodium nitrite promoted the passivation of crystal grains.

Keywords: carbon steel; intergranular corrosion; electrochemical characteristic; carbonic acid; sodium nitrite

\section{$\underline{\text { FULL TEXT }}$}

(C) 2016 The Authors. Published by ESG (www.electrochemsci.org). This article is an open access article distributed under the terms and conditions of the Creative Commons Attribution license (http://creativecommons.org/licenses/by/4.0/). 